\title{
The tales of the three digital cities of Amsterdam: The application of ICT for social and political participation
}

Dennis Beckers ${ }^{1}$

Peter van den Besselaar

Department of Organization Sciences, Vrije Universiteit, Amsterdam, The Netherlands

doi:10.5937/comman1430115B

Summary: During the last decade, many European digital cities applied ICT to improve the local public sphere, reinforce local democracy, support local communities and increase social participation. Different policies of a variety of stakeholders led to a wide variation of designs and functionality, content, main actors, aims and philosophy, organization, and use and users. To build a useful and sustainable online environment (digital city) proved to be difficult. Political changes, economic cycles or changing priorities of funders threatened the existence of digital cities. This article gives an historical overview of the development process of digital cities during the last fifteen years in Amsterdam to get a better understanding of this variation. It tells the stories of three Amsterdam digital cities, identifies the main actors, tries to explain the observed variations and discusses the role of these digital cities for social and political participation.

Keywords: digital cities, civic networks, public sphere, digital democracy, social cohesion

\section{Introduction}

Before the rise of social media as Facebook and LinkedIn, and other social media, online local initiatives were, and still are, connecting inhabitants of cities. Technological innovations as the personal computer, the modem and

\footnotetext{
1 mail@dennisbeckers.nl
} 
the Internet created in the 1980s and 90s a new digital infrastructure that influenced the dynamics of urban life. They changed the nature of interpersonal relations and communications and the form and substance of participation and cohesion in society.

During the first decade of public Internet, many European cities build a digital equivalent of their urban space. Several historical, political and technological developments converged and gave birth to a new social and technological constitution: the digital city, broadly described as an on-line platform associated with a city or region for citizens, businesses and visitors.

The urban dynamics resulting from the innovations in ICT were not uniform and homogeneous among cities. As with previous technological innovations, there were many variations in the implementation and use and the way they are institutionally embedded. This diversity shows the effect of the process of social shaping of technological systems. It means that the roles and policies of the many stakeholders in the city are important (however not determining) in shaping the processes of change and their outcomes. The diversity resulted in many kinds of digital cities that differ in their features, appearance and organizational form: community networks and grassroots communities (Schuler, 1996), municipal information and communication networks, online communities (Beamish, 1995; Preece, 2000), multimedia technologies for public services (Williams, Slack and Stewart, 2000), virtual communities (Rheingold, 1993), tele-community systems, civic networking (London, 1997), public electronic networks (Harrison, 1995; Schmidt, 1997), cyber-communities (Kollock and Smith, 1998), city oriented commercial web sites, portals and many other forms.

The expectations of the effects on social and political participation of these forms of community informatics were high. These forms of locally grounded social media would not replace but augment the old ways of communication and the transportation of information, and the resulting complex dynamics would change the constitution of the communities of inhabitants and the relationship between local governments and citizens.

While some researches in community informatics showed a positive tendency on the results of ICT in a community, see for example Schuler (1996), Foth (2011) and Longford (2006), others concluded that community networks in general were seemingly unable to become recognized players in the decision- 
making process at the local level and that the impact of digital cities on the life of citizens was limited. Many digital cities eventually became stagnant or closed down, or evolved into a web site of a local institution with only a marginal role for citizens (De Cindio and Schuler, 2012).

This article provides a history of Amsterdam's digital cities. It discusses the development process of these three digital cities during the last fifteen years: $D D S$, the former digital city of Amsterdam (2000-2004), Cyburg, an online system for a city district (2006-2008) and Buurtleven ('neighborhood life') (20082010). We try to explain the observed differences and discuss their capacity to allow for participation within their websites, and their role in strengthening social cohesion and political participation in Amsterdam.

\section{Methodology}

The broad methodological approach reflected in this paper is that of community informatics (Longford, 2005). The topic of this interdisciplinary research field is the study of uses of ICT in communities and the impact of ICT on a community's social, economic, cultural and political goals (Gurstein, 2000). Community informatics brings together the perspectives of stakeholders as citizens, community activists and groups, policymakers together with a range of academics working across disciplines (communication studies, cultural studies, computer science, information studies, sociology, political science and urban studies).

Community informatics research and practice are also linked to the theoretical understanding of the development of technology that recognizes the social shaping of technology. Theories of the social shaping or social construction of technology reject technological determinism, which tends to treat technology as an autonomous force acting on society in a one-way relationship, in favor of the view that society and technology are mutually conditioning (Bijker, 1995; Longford, 2005; Wyatt, 1998). For this article, we follow the following narrative of the pattern of development of technologies:

Technologies are social constructions, the outcome of negotiation between relevant social groups. To explain technological developments we need to identify who is involved and what their interests are. In any innovative effort, actors form alliances. A project often has certain interpretative 
flexibility, when there exist competing meanings. The selection of one of many possible solutions is also a social process. Often there is a key actor/ entrepreneur who is instrumental in enrolling other actors and defining the scope of the technological frame. A successful mobilization of arguments, interests or resources may result in closure: the artifacts become stable and enter a wider world. But users of technical artifacts and systems also possess a degree of what could be described as interpretative flexibility: malleability. New artifacts may or may not work, and may or may not be used. Some might fail or be used in unforeseen ways. If the technology fits within the technological frame of its wider community of users, it might acquire momentum. In this way, successful technologies give appearance of autonomy. (Wyatt, 1998: 17)

To investigate the phenomena of the digital city and its context, we conducted 18 interviews with the main actors at each digital city, buttressed by other sources of information as memos and minutes or other forms of 'hard' evidence. For gathering characteristics of the users, we conducted online surveys with users of DDS (1,300 respondents in 1996 and 700 in 1998) and Cyburg (502 respondents in 2003), containing questions on social demographical characteristics (gender, age, area of residence, education, main occupation, income, political preference, active in political or social organizations) and ICT related questions (experience with the Internet, connection with the Internet (from where and speed), Internet provider, start date using the Internet and start using the digital city). To get insight in the usage of the digital city, the survey for the users also contained questions about how often, how long, and what parts of the digital city the respondent used. Also, for DDS and Buurtleven a log-file analysis was conducted where we categorized the content of the digital cities and counted how often users visited content in these categories.

The first main section of this article describes themes emerging from the literature on the relationship between the technological innovations in ICT and its effects on social and political participation in urban areas. The second section presents the empirical findings of the research. For three digital cities of Amsterdam the network of actors is mapped and their roles for the organization and goals are described. Also, we describe the organizational structures, the way the digital cities were funded and the user population and their use of the digital city. In the conclusion we try to explain the observed differences 
and describe the role of the digital cities for social and political participation in Amsterdam.

\section{Digital cities and participation}

The sociotechnical environment of digital cities is complex and dynamic. The systems were not grafted onto the existing cities, but being integrated in existing social structures (Shuler and Day, 2004). It is therefore necessary to discuss some literature to place the phenomenon of digital cities in their context and to investigate the socio-technological processes that substantiate its development.

The next sections discuss some issues political and scholarly debates have brought up in the debate on the effects of ICT on social participation, as the social participation in the community (section 1.1) and in local political participation (section 1.2).

\section{ICT and social participation in the local community}

The rise of new technologies impacts the constitution of local communities. Tönnies (2002) saw a connection between modernity and the on-going degeneration of social structures. Industrialization caused a trend from Gemeinshaft to Gesellschaft, from social relations between people based on specific ethnic, religious, linguistic or geographical borders, to a form of strong individualism where relations are mechanical, transitory and contractually oriented. In this way the process of industrialization and urbanization would lead to the decline of the community and thus of the traditional safety and intimacy of the traditional community. Putnam (2000) showed how participation in social activities in the US grew steadily from the early part of the century until the 1960s, with a dip during the depression, and then has steadily declined ever since. Americans have become disconnected from one another and spend less time together, both formally and informally. Putnam presents a number of reasons for this decline of participation in social activities: television, the entry of women in the workforce (since women do a lot more organizing of social events than men), and urban sprawl, since it takes a lot more time and effort to see friends or attend events. Although Putnam's observations are focused on the US, and issues as urban sprawl are less relevant for the situation in Europe, in all Western 
countries a steady decline in civic engagement has been observed. According to Putman, one of the most pressing questions for the future is how to reverse this decline in social capital and restore civic engagement as this decline is correlated with lower trust, higher crime and higher stress levels among individuals.

The emergence of the Internet resulted in the rise of new patterns of social interaction (Castells, 2001). ICT provided the possibilities for an online platform to re-strengthen local communities. Communities became able to organize themselves online and citizens could online participate in activities in the (broader) community.

The hopes of these kinds of platforms were high. Kling (1996) coined the term "cyber utopia" to describe the utopian visions of communities whose members interact primarily on-line. These visions were often based on simple technological determinism and utopianism, and tend to evangelize and hype up the transformative powers of telematics (Kling, 1996). Others were less enthusiastic, and pointed out that online communication reduced real-time sociability and entices individuals to live their own fantasies online, thereby escaping the real world, thereby contributing to the further decline of social and political participation.

Hampton and Wellman (2002) concluded that, based on their analysis of networks, a trend is visible that transforms the social surrounding of people from the tradition geographically based community into a diffuse network. In modern cities people still share proximity, but they are often atomized and do not necessary form a community. Instead, people live in loosely connected and often changing networks. Still, for the local level, Hampton concluded that, as home-computers and residential networks became prevalent, the Internet was increasingly used to expand neighborhood social capital and therefore actually could serve to reverse the decline of social capital as it enhanced sociability both at distance and in local communities (Hampton and Wellman, 2002).

\section{ICT and political participation}

Nearly thirty years before the rise of the public Internet, Habermas (1962) described the public sphere, a model where individuals are able to freely share their views with one another outside of the realm of government and the economy. Since then, Habermas's coffeehouse discourse has evolved in the direction of online communication. While radio and television tended to be closed to 
critical and oppositional voices, both in systems controlled by the state and by private corporations, the rise of the Internet expands the realm for democratic participation and debate and creates new public spaces for political intervention, thereby expanding and redefining the public sphere. Some hoped that the rules of Habermas's "ideal speech situation" could be transferred to electronic networks so the (local) democracy could truly represent both citizen and community interests.

During the early 1990s, authors as Rheingold (1993) saw great possibilities in the use of ICT to improve (local) democratic processes. The openness of expression which "the ideal speech situation" demands can be applied to Internet, where rapid exchange of dialogue and production of information take place unchecked, thus providing an virtual online public sphere what reactivated the grassroots of an egalitarian public of writers and readers (Boeder, 2005).

Around the world there have been many initiatives to utilize ICT to underpin the creation of a more participatory and democratic vision of the network society. Digital cites could enhancing democratic processes by increasing public participation in the decision making processes, providing access to government information, increasing transparency and accountability of (local) politics and keeping the government closer to the consent of the public.

Central to the notion of Habermas's public sphere is the notion of participation, as within the public sphere citizens participate in the formation of public opinion, which in turn can impact upon the realm of politics. During the first ten years, the discussion on online participation and the digital divide focused mainly on access to online environments. As after the turn of the millennium in Europe access is nearly universal, Gurstein (2007) went beyond this issue and introduced the concept of "effective use", pointing at how ICT could be used for implementing applications and services in support of local communities. For the local application of ICT, participation has to be bolstered across demographic areas, specifically amongst those groups that are socially and economically vulnerable - as (ethnical) minorities, unemployed, elderly and handicapped, as information illiteracy might result in the lack of political power to enact the necessary changes to their condition.

There are positive reports about the application of ICT for transforming and strengthen local politics (DIAC, 2004). There are also critical results. Laffin and Ormston (2013) conclude that ICT applications have limited capacity 
to radically transform the public policy process and the delivery of complex public services. For Europe, the results of De Cindio and Schuler (2012) offer some explanations, as the conceptualization or framing by politicians, the lack of political will as local governments in Europe were far from being aware of the importance of listening, interacting and involving citizens. Although the awareness and even usefulness for the possibility of citizen participation became stronger, it is still more a good intention and an electoral promise than an actual policy implemented with concrete actions. But also the community networks bear some responsibility: discussions were often dysfunctional and rarely ended with some an explicit and agreed-upon conclusion.

\section{Three Amsterdam Digital cities}

The previous section described some common principles and a theoretical background of digital cities for the participation within the digital cities, social cohesion and political participation. The next section tells the stories of three digital cities in Amsterdam: (DDS, 1994-2000), the former digital city of Amsterdam, Cyburg (2000-2003), an online system for a city district and Buurtleven ("neighborhood life", 2009-2011).

\section{DDS (1994-2000)}

On $15^{\text {th }}$ January 1994 many Dutch people heard for the first time about the Internet. At that day the digital city $\left(\mathrm{DDS}^{2}\right)$ opened its doors. From the beginning on it was highly successful, both in number of users as in media attention. On its heydays DDS claimed to have over 180,000 members and it was one of the most well-known digital cities in Europe. Not only in the Netherlands, but also in other countries, DDS has been very influential in the way people think about what a digital city was.

During its lifetime, DDS has known three major organizational forms. It started as a bottom-up experiment, became a non-profit organization and changed in 2000 into a commercial organization, until eventually in the beginning of 2001 the online environment was closed down. During those years, the Internet and the market for Internet applications changed dramatically.

\footnotetext{
DDS is the abbreviation of "De Digitale Stad", Dutch for The Digital City.
} 
Funding, or the lack thereof, has been an important reason for the changes; in the first stage of the project DDS relied on grants from the municipality and national ministry, while later DDS had to provide its own funding by consulting and building web sites for other organizations. With this shift in funding, also the allocation of resources changed from the digital city towards the commercial projects.

Figure 1 shows the first and third version of the interface of DDS. In the interfaces, the metaphor of the city was used to help inexperienced users and to convey the sense being in a city.

Figure 1: The first and third interface of DDS
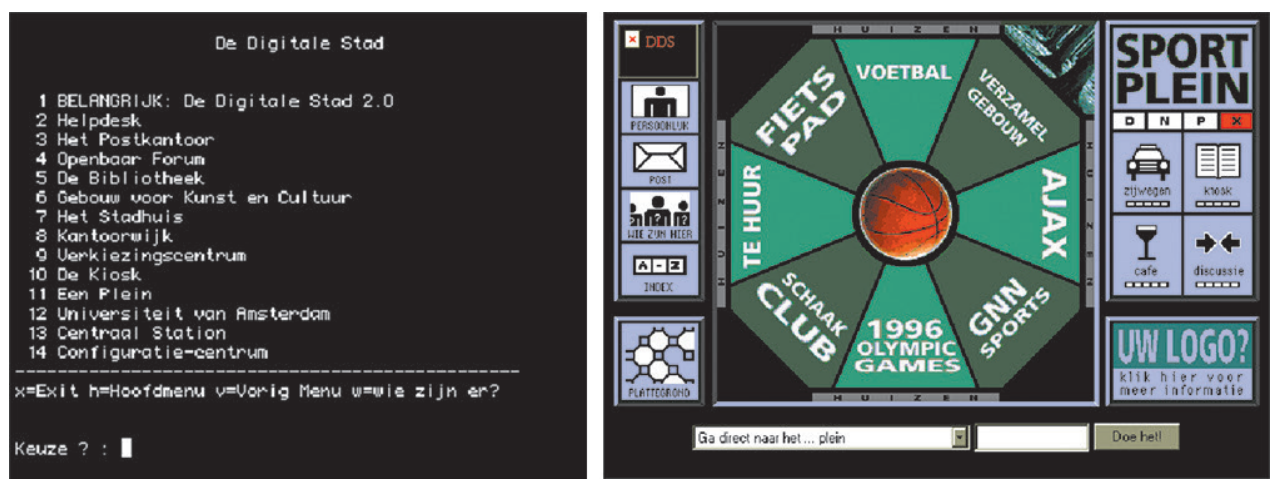

The network of actors of DDS consisted of a diverse group of organizations and individuals, as by enrolling the HackTic Network, cultural center "de Balie", the municipality of Amsterdam and volunteers of various cultural organizations. The number of involved organizations decreased soon after the end of the experimental period. In the second year the structure of the actor network changed, but also the role of the individual actors changes. The initiators started a loose and informally bound group focused on the virtual space. This changed into a foundation with a management-team and employees. After the breaking up of the actor-network, financially DDS was mainly on its own.

Although during its lifetime much changed in and around DDS, the management has been remarkably constant. While the group of actors involved with DDS, the organizational structure and the political and technical context changed over time, only two persons have been in charge of DDS. Until 1995 Stikker performed this role and since then Flint was managing director, during 
the last years assisted by Göbel. In interviews, Stikker and Flint both agreed that their personal influence on DDS has been large, and that the history of DDS is in part also their personal story. This implies that when other persons might have been in that position, the history of DDS could have been very different.

User participation has never played important role at DDS. During the experimental phase, the division of 'users' and 'developers' was not strict. This changed after the end of the experimental phase, when the coalition of actors broke up and the initiators of DDS were forced to shift the allocation of resources from the digital city towards commercial projects.

The goals of DDS were a hotchpotch of the interests of the participating organizations. The designers of DDS shared a fascination with new technologies and an interest in politics. There interests are reflected in the technological and political goals of DDS. The main reason for the hackers to participate were their goals of social participation, freedom of expression and the engagement with rules and regulation of the virtual public space. The cultural center "de Balie" was visible in the goal to support cultural organizations and the willingness to experiment with technological innovations for new media. Last, the government was visible in the goals on participation, democracy, knowledge development and transfer and economic development.

At the end of the first phase and after the actor-network dissolved, the goals of DDS changed. When HackTic terminated its involvement, providing access was no longer a priority for DDS. The goal of providing an online public space got less attention, while developing (commercial) projects became the main focus. For the municipality it was a deliberate choice not to be responsible for a virtual public domain and to stop the cooperation with DDS. With their departure, the priorities for political goals were lowered.

In order to be able to attract investors and to make the structure of the organization more clear, the organizational structure of DDS changed again in March 2000. At the peak of the Internet hype, DDS changed from a foundation into a holding company. The shares came into the hands of the management. The holding company contained four independent companies of which one focused exclusively on the digital city as an infrastructure for communities and sheltered all semi-public activities. Some expected there would be more resources for maintenance and further development as funding would be pro- 
vided by the three other Ltd's and DDS would retain its idealistic character. However, this optimism proved to be ungrounded. In the course of the year 2000 the 'internet bubble' burst and many potential investors suffered from the sudden deteriorated financial climate for Internet companies. To cope with the continuing problems of funding, at the end of the year 2000 the board of DDS announced that editorial activities were discontinued and three editors were laid off. One month later, the complete holding DDS services Ltd was sold to a big telecom and Internet service provider. On the beginning of 2001 the digital city was closed down and DDS City Ltd. was reduced to a regular Internet Service Provider.

\section{Cyburg (2000-2003)}

Nearly ten years after the start of DDS, Amsterdam got another digital city: Cyburg, aimed at the residents and organizations in the city district Zeeburg. In contrast to many other digital cities, Cyburg had a professional staff working exclusively on the system.

In 1999 a nationwide contest was called for to elect a city for experimenting with various ICT-innovation. Although Amsterdam did not win, it decided to persevere the plans to build a 'knowledge neighborhood'. This project got funds from the European Union, the national government, the province of North Holland and the Amsterdam municipality.

The goal of Cyburg was to build an online platform and to serve as an experimental area for research on the development and application of ICT for individuals, companies and local authorities in urban districts. In the long run, those applications and concepts that proved their worth should become available for other city districts. Within the Cyburg project a number of focus areas were formulated, including the social participation of citizens. One goal of the project was to improve quality of life by stimulating social contacts between citizens by means of ICT. Other priority areas of the Cyburg project were to bring politics closer to citizens, to stimulate local companies and to improve municipality services.

Cyburg hired professional journalists who edited the news bulletins on events in Zeeburg, as the website of Cyburg consisted among others of a portal for the neighborhood, see Figure 2. 
Figure 2: Interface of Cyburg

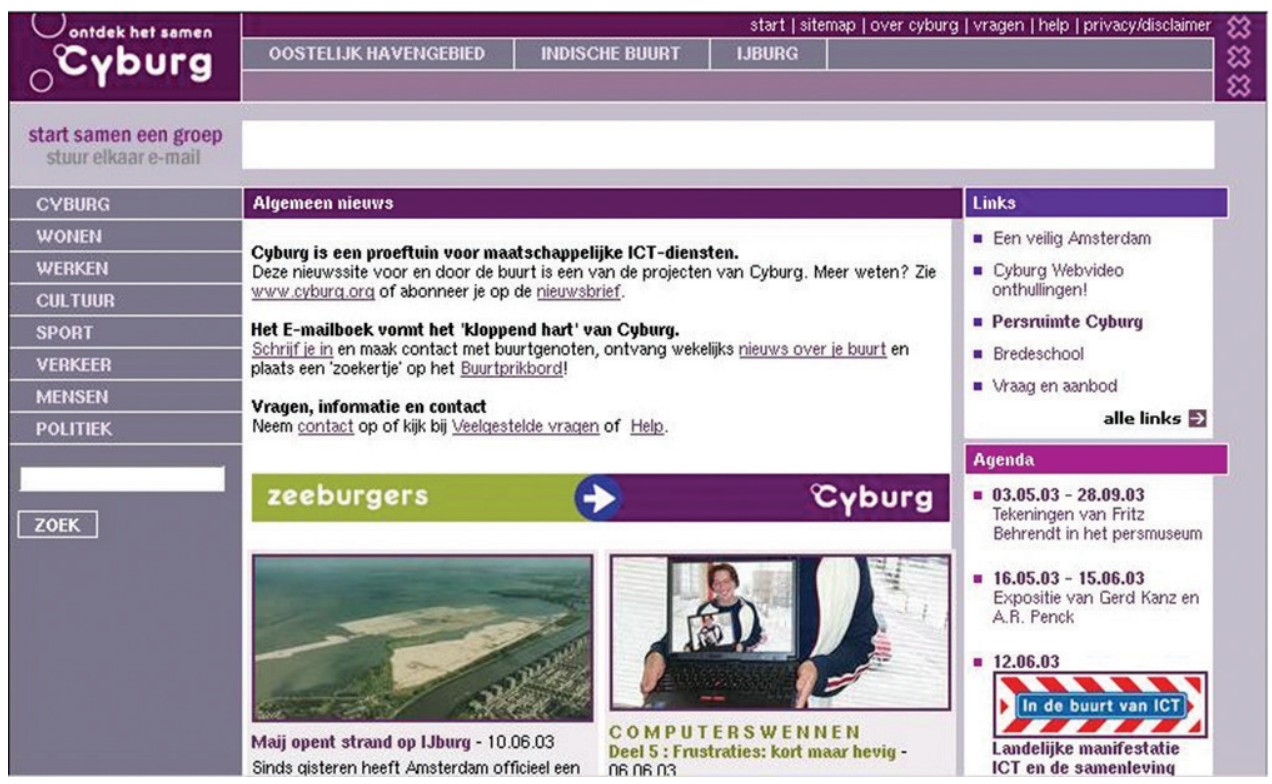

Residents of Zeeburg could also place their messages on the website, add their comments to already placed bulletins, or react to the comments of others. Another important part of Cyburg.nl was the 'email book', allowing users of Cyburg to contact their neighbors and form online groups. The email book could be used anonymously and users got a Cyburg email address so their own email address remains invisible. Cyburg also offered mailing lists, the functionality for sharing documents and pictures and a forum for group discussions. Finally, users could place small ads. In addition to the website, the Cyburg organization supported various projects for groups of citizens and companies. The focus of these projects was on social surroundings, stimulating economic innovations and experiments for improving municipality and non-profit services for citizens. Cyburg also tried to be actively involved in the discussion on the application of broadband Internet. Another goal of Cyburg was to facilitate initiatives from the neighborhood. Although at the start there were some contacts with inhabitants, in the end there was little cooperation between Cyburg and local initiatives. According to those initiatives, they felt Cyburg was a cumbersome and slow organization. It often took a long time before decisions were made. Also, for the respondents it was sometimes unclear who in the or- 
ganization should be contacted, or they had the feeling to be sent from pillar to post. Respondents were also surprised about the redundant work Cyburg did. For example, there were already various web sites that provided news about the neighborhood before Cyburg started to do the same. Finally, Cyburg was experienced as 'top-down' instead of being part of the neighborhood. Halfway the experiment, this was also realized by the Cyburg organization. The new slogan became "high interaction, low tech" to indicate that interaction with the neighborhood had become more important than technology.

The results of our telephonic survey among 500 inhabitants of the city districts showed half of the residents were aware of Cyburg, but only four percent actually used it. Reasons for this low usage were the unclear goals of the website, the complicated structure and technological problems. The survey among users shows Cyburg.nl was mainly used by highly educated Dutch males with a lot of online experience, quite similar to the characteristics of the user population found at DDS. Other groups, who could benefit more from the websites compared to those who already have a head start because of their background, hardly use the website. Ten years after DDS, the case of Cyburg showed it was not easy to get residents involved with a website aimed at the neighborhood. The Cyburg project ended at the end of 2003, but some projects continued for some time.

In terms of numbers of users and usage, and increasing social participation in the city district, Cyburg was not a great success. While other local websites in the same district were successful in providing a useful platform for (future) residents of Zeeburg, Cyburg was not. The organization presented the system as an online environment for residents and local organizations. However, especially during the first year, the focus of the organization was more on technical issues than on bonding to already existing social networks and relevant organizations in Zeeburg. As a result, most citizens did not know about Cyburg, and those who did saw little use in it. In terms of the actor network, the foundation responsible for Cyburg failed to see the importance of enrolling other partners into their actor-network. Local organizations perceived Cyburg as a product of a typical top-down approach by the municipality, and were therefore not very interested in cooperation. By not enrolling other groups, Cyburg became isolated. This, in combination with some technical problems and the, for residents 
and organizations unclear purpose of Cyburg, resulted in the low usage of the system.

\section{Buurtleven (2009-2011)}

Buurtleven.nl was, after DDS and Cyburg, the third major online initiative in Amsterdam. The project would exist for five years, but was cancelled after only two.

The initiative for Buurtleven came from four Amsterdam building cooperatives that invested in a fiberglass network in parts of Amsterdam. This raised the question what services they could provide over this network that would connect with the societal goals of the cooperatives. The idea came up to provide every home with a private e-mail address and to provide all 80,000 homes in four districts of Amsterdam with a digital mailbox. The cooperatives could use it for their communication to their tenants, and residents and local organizations could use these addresses to get in contact with each other. In this way Buurtleven.nl would promote social cohesion (Schüller, 2008).

A project group presented a business case in February 2007, and a few months later a project was established to draft a functional and technical design and an extensive business plan. In March 2008 the project group presented the final business plan. The idea of the electronic mailbox was extended: the system, now called "Buurtleven.nl" (neighborhood life), would also present neighborhood news and provide a stage for individuals and local organizations. The aim was to improve the livability of neighborhoods, by facilitating contact between residents. Also Buurtleven provide housing associations and their tenants with a new way of communication. Tenants would find information about their living situation, report complaints and online contact the caretaker. Buurtleven would also provide a platform for communication between residents committees and their members.

The cooperations would finance Buurtleven for five years. After those years, the organization should be financially independent by advertising revenue and agreements with partners. It was decided to start only in the areas were the fiberglass infrastructure was installed: 77,000 households, of which 47,000 rented from the cooperatives. Of the residents, more than half (52\%) are first or second generation immigrants. 
In February 2009 Job Cohen, the former mayor of Amsterdam, opened Buurtleven.nl. On behalf of the mayor, 100,000 invitations were sent to residents to participate in Buurtleven. After half a year, ten percent of the residents had registered. In order to persuade the residents to use Buurtleven. $\mathrm{nl}$, the team decided to start providing news on the local neighborhood. Buurtleven.nl got a professional editor and a network of freelance neighborhood correspondents.

The decision to only be active in the area with fiberglass was found to be a hindrance, as only part of the audience and organizations in the city could use Buurtleven and it was of little interest for advertisers and sponsors. Late 2009 it was decided to make Buurtleven.nl accessible for all Amsterdam residents. To cover the whole city, extra news editors were employed.

The participation of local organizations (welfare organizations, community directors, tenants' organizations, cultural institutions, schools, local businesses and health centers) was low. Local organizations did see the potential of Buurtleven.nl, but often used it only for posting messages. In this way Buurtleven.nl was only used as a transmission channel, instead of an interactive medium.

Also the participation of the cooperatives was disappointing. When Buurtleven was contrived, the cooperatives benefited from the economic boom. Around the launch of Buurtleven the economy turned and the cooperatives got financial problems, resulting in reorganizations and dissolving attention for Buurtleven. At management level cooperation was promised, but at the implementation level the interest to work with Buurtleven was very low. The original plan of the cooperatives to communicate with the residents via Buurtleven.nl was barely working. For tenants, there was therefore no need to use Buurtleven.nl.

The users' levels of activity and the interaction between users of Buurtleven. $\mathrm{nl}$ was low. The site provided little reason and limited opportunities for interaction, the procedure for registering was complicated, the user friendliness of the interface was not optimal and the information residents could put in their profiles was limited. The goal of Buurtleven.nl for contributing to social participation proved to be infeasible as the effects on social cohesion remained unclear and could not be demonstrated. The awareness of Buurtleven was low among the residents (even comparable with Cyburg.nl) and relative few inhabitants activated their access code. During the two years the number of users increased 
slowly but steadily, but involvement of inhabitants was limited and no online community developed. Eventually Buurtleven.nl was hardly an online community for neighbors but was regarded by the users as local news website.

\section{Figure 3: Interface Buurtleven}

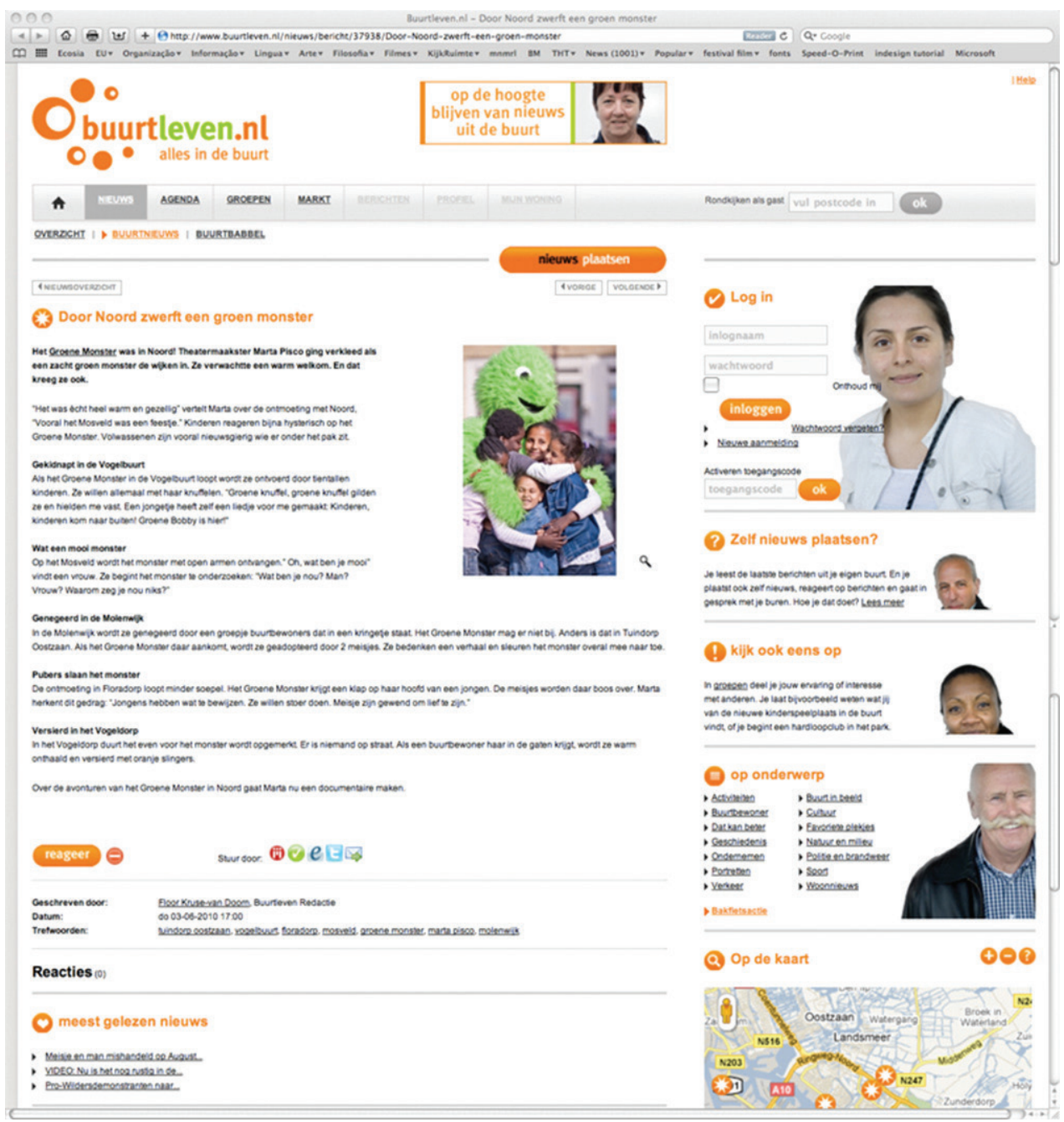

In the business plan and long-term budget of 2008 it was assumed that Buurtleven would generate enough revenues to sustain itself, by providing services to other local organizations. But due to lack of interest it became clear soon that Buurtleven would not become self-financing. 
In June 2010, the cooperatives let know to have little faith in the survival of Buurtleven. A trial period was agreed until November 2010. The project manager was replaced and the Buurtleven-team was expanded with a community manager. A second version of the site was presented in April. The interface was more user friendly and the registration procedure simplified.

The team felt that with these measures Buurtleven would become a success. At the end of the trial the cooperatives concluded positive trends were visible, but the effects of Buurtleven.nl on the community were not substantial enough to continue. When an external consultant concluded that the business model of Buurtleven was not viable and advised to discontinue the site in its current form, the cooperatives decided to cancel Buurtleven. The official reason was that social media like Facebook overtook it. But before this conclusion was reached the cooperatives already lost their trust in Buurtleven. On $1^{\text {st }}$ January 2011 the server went offline. Although there was pronounced that the cooperatives would continue to explore the possibilities for other initiatives, after closing Buurtleven the actor-network disintegrated.

\section{Conclusions}

Digital cities, on-line platforms associated with a city or region for citizens, businesses and visitors, took the application of computers for communication from fantasies portrayed in movies ${ }^{3}$ to the living room. Since the proliferation of PC's and the Internet, many cities experimented with the application of ICT for increasing social and political participation to soften or remedy problems as declining social cohesion and civic engagement. As such, digital cities have been the object of enormous hope and considerable disappointment. This article provides an historical overview of the development processes of these three digital cities, focusing on the participation of various actors in the organization of the digital cities, and the role of these digital cities for social and political participation.

For many European citizens, digital cities provided the first opportunity to explore an online environment. The metaphor of the city and the enthusiastic coverage of the media helped to familiarize the general public with terms as electronic bulletin boards, e-mail and the World Wide Web.

\footnotetext{
3 Among others “Tron” (1982), "War games” (1983), and “The Lawnmower Man” (1992)
} 
In Amsterdam, between 1994 and 2010 three digital cities were built. The characteristics of digital cities discussed were not uniform and homogeneous, but differed according to design and functionality, content, main actors, aims and philosophy, organization, use and users. The case studies show that digital cities were products of the technological and prevailing socio-political climate.

To build a useful and sustainable digital city proved to be difficult. Political changes, economic cycles or changing priorities of funders make that digital cities were never sure of their income. In order to provide an information and communication service to the users, there were substantial costs that must be financed. Besides the cost to keep the service up and running, competition with other alternatives made innovation, or at least keeping up with technical development, necessary and for that funds were needed. All three digital cities employed a considerable professional staff, so a steady income was required. Cyburg was paid for by European and local governments, so here funding was a smaller issue.

Finding a suitable model for sustainable funding proved to be difficult. The digital cities tried several funding models. For DDS generating income from advertising proved to be very difficult, especially after the burst of the Internet bubble in 2000. Gradually the focus of DDS shifted from the digital city towards the projects, spending less time and energy on the online community, resulting in technical problems, slower innovations and eventually abandoning users. Years later, Buurtleven also found out that its business model based on advertisement revenues and providing services for other organizations was not feasible. A purely commercial business model for digital cities seems to be very difficult.

Another cause for the hard time many digital cities experience was the increased number of available alternatives. When DDS started in 1994, there was no public access to the Internet in the Netherlands yet, let alone a place to build an own web site. During the next years free e-mail and home pages were no longer unique (although often with advertisement) and the portal function of digital cities got competition from other search engines and commercial indexes. Various free Internet Service Providers offer free access to the Internet and schools and universities offer access for their students. The notion of 'community' became hype and many competitors started to offer free infrastructure for online communities and digital cities. However, besides offering informa- 
tion about tourist attractions and a chat box, these commercial digital cities did little for the original goals of most digital cities such as education, rebuilding democratic processes in the city by providing a digital public space and reinforcing the local community by stimulating social participation.

Eventually, none of the digital cities proved durable. DDS existed for six years, Cyburg and Buurtleven for two. Problems with funding, difficulties in building a critical mass of users, technological problems and increasing competition of other social media made that all three digital cities eventually closed down.

\section{Participation within digital cities}

Many different types of actors were involved in the digital cities such as a cultural center, (local) government institutions, housing cooperations, hackers, et cetera. The same technology (the digital city) meant different things for different actors. Also, the life story of a digital city was often connected to the personal history of one person (in terms of STS, the 'translator') and his or hers ideas, emotions, goals and opinions. For nearly every digital city there was a person who was strongly connected to the development process of the digital city and who has great influence on crucial decisions and characteristics of the digital city.

The goals of a digital city should be interpreted in the specific time and stage of development of ICT and were related to the characteristics of the main actors, as every member of the alliances had its own interpretation of what a digital city could mean. All actors have their own agenda, so keeping the alliance of actors together proved to be an on-going process. Conflicts of interests, disagreements and changing interests resulted in stagnation, organizations dropping out or eventually the breaking up of the alliance and the closure of digital cities.

DDS was an experiment in every respect. It was an experiment with new technology, with social aspects of being online and with the organizational structure. During the first experimental phase of DDS, Stikker engaged a cultural center, local government, group of hackers and many social organizations to cooperate and provide content and services to DDS. For the cultural center DDS was an experiment with new forms of communication, while the local government saw DDS as a way to experiment with new forms of democracy. For the hackers it was an opportunity to build an infrastructure and show their capabilities. 
Six years later, when Cyburg started in 2000, technology had developed fast and the Internet was established. Cyburg was also experimental, but in their publications could have focused more on the social applications than on the technological aspects. In reality, the organization focused, especially during the first year, strongly on the development of their website, while building connections with the neighborhood got less attention. Founded in 2009, Buurtleven was not experimental, but had practical goals, closely related to those of the housing cooperations. While there was a link between the kind of actors involved and the features and goals of the digital city, this was not a direct link, as economic, social and political contexts were also important. Table 1 provides an overview of the main actors and their interests and goals of the three digital cities.

Table 1: Digital cities, main actors and their interests and goals

\begin{tabular}{|l|l|l|}
\cline { 2 - 3 } \multicolumn{1}{c|}{} & Alliance members & Interests and goals \\
\hline \multirow{4}{*}{ DDS } & Local government & $\begin{array}{l}\text { Experimenting with new forms of democ- } \\
\text { racy }\end{array}$ \\
\cline { 2 - 3 } Cyburg & Cultural center & Experiment with new medium \\
\cline { 2 - 3 } & Hackers & $\begin{array}{l}\text { Proving to be able to be constructive, ex- } \\
\text { periment, educate }\end{array}$ \\
\hline \multirow{3}{*}{ Buurtleven } & $\begin{array}{l}\text { Foundation } \\
\text { Amsterdam } \\
\text { Knowledge } \\
\text { city Cyburg }\end{array}$ & $\begin{array}{l}\text { To serve as an experimental area for re- } \\
\text { search on the development and application } \\
\text { of ICT for individuals, companies and local } \\
\text { authorities }\end{array}$ \\
\hline $\begin{array}{l}\text { Four Amsterdam } \\
\text { cooperations }\end{array}$ & $\begin{array}{l}\text { To improve livability of neighborhoods, by } \\
\text { facilitating contact between residents } \\
\text { To provide housing associations and their } \\
\text { tenants with a new way of communication }\end{array}$ \\
\hline
\end{tabular}

Users are noticeably absent as main actors, this in contrast to the dominant idea of community networks as grassroots activities, as is the case in US-based Freenets and civic networks. The three cases in Amsterdam all had a top-down organizational structure, without the possibility for the users to influence the policy of the organizations. In all three cases there was a strict distinction be- 
tween staff and users. Users were seen as consumers rather than participating actors. They could provide content but could not participate in decisions at board level. It is remarkable that the (future) users of these three digital cities were not or hardly involved during their development processes. For the first iteration of DDS, a reason for this might have been that there were only few users experienced with online systems. DDS after the experimental phase, Cyburg and Buurtleven might have benefited from a more bottom-up approach and more user involvement.

\section{Social cohesion}

The three digital cities all facilitate online communication in various ways and there are many anecdotes of individuals who found meaningful relationships in digital cities. Still for these three cases it is hard to find evidence for the claim that a digital city improves social cohesion for the city as a whole. For DDS, improving social cohesion was not a specific goal. The user population was too skewed towards the young and technology savvy. It might be that DDS connected individuals or interest groups, but not the scale of the city. For Cyburg, the number of users was simply too low to have a significant effect. The effects found could also be attributed to other variables as education, age and household income. Finally, Buurtleven, the number of users was also relatively low, and the system was more used as a local news site than an online public space.

\section{Political participation through the digital cities}

All three digital cities did provided a platform for discussion. However, the impact of these discussions were very limited.

These were not outside of the realm of government and the economy, as Habermas's public sphere was supposed to be, as these digital cities were depending on other institutions for funding and other support. Therefore these platforms were not 'public spheres' in the strict sense of this term.

Besides this more theoretical viewpoint, the results of the surveys show the digital cities were mainly used by high-educated males, while less educated, elderly and immigrants were underrepresented. The same critique on Habermas's public sphere therefore also applies to digital cities: only a small group of elite 
is using the possibilities to discuss local politics, while most of the others spend their time online chatting on more 'trivial' subjects and online games. Moreover, the translation of (elitist) public opinion into the realm of politics remains difficult anyhow.

The results of the content analysis and interviews shows that the level of political discussion and its impact were limited. The case of DDS illustrates this. Although in DDS, over a third of the newsgroups were focused on social and political issues, soon doubts about the level of the discussion were expressed (Besselaar and Beckers, 2004). And although an aim was to improve communication between residents and local politicians, hardly any politician participated.

\section{Postscript}

While DDS introduced many Amsterdam citizens to life online, the next two digital cities were not the success hoped for. In the meantime Amsterdam residents found other online platforms to get together, play together and discuss politics. Technological progress during the last decade made it relatively easy to build a location based online community, with or without the use of platforms as Facebook, LinkedIn or Twitter. Recently there have been several examples of successful hyperlocals in Amsterdam, bottom up blogs or sites aimed at a small geographical area as a district, neighborhood or street. These hyperlocals, became possible since platforms for blogging became easy to set up and maintain by volunteers. Although beyond the scope of this article, it is the question if these hyperlocals will follow the pattern of DDS and eventually become institutions, or that this is the start of a new phenomenon with its own dynamics. 


\section{References}

Beamish, A. (1995). Communities on-line. Community-based computer networks. MassachusettsInstituteof Technology, Cambridge,Mass.Accessed20.12.2013. URL: dspace.mit.edu/bitstream/handle/1721.1/11860/32905494.pdf.

Besselaar, P. van den \& Beckers, D. (2004). The life and death of the great Amsterdam Digital City. In Besselaar, P. van den \& Koizumi, S. (eds.), Digital Cities 3. Information technologies for social capital. Lecture notes in computer science. Berlin: Springer-Verlag, pp. 70-99.

Bijker, W. E. (1995). Of bicycles, bakelites, and bulbs: Toward a theory of sociotechnical change. Cambridge, Mass.: Massachusetts Institute of Technology.

Boeder, P. (2005). Habermas' heritage: The future of the public sphere in the network society. First Monday, 10(9). Accessed 20.12.2013. URL: http:// firstmonday.org/ojs/index.php/fm/article/view/1280/1200.

Castells, M. (2001). The Internet Galaxy: Reflexions on the Internet, business, and society. Oxford: Oxford University Press.

De Cindio, F. \& Schuler, D. (2012). Beyond community networks: From local to global, from participation to deliberation. The journal of community informatics, 8(3). Accessed 20.12.2013. URL: http://ci-journal.net/index. $\mathrm{php/ciej/article/view/908,}$

DIAC (Conference). (2004). Shaping the network society: the new role of civil society in cyberspace. Cambridge, Mass: MIT Press.

Foth, M. (2011). From social butterfly to engaged citizen?: Urban informatics, social media, ubiquitous computing, and mobile technology to support citizen engagement. Cambridge, Mass.: MIT Press. Accessed: 20.12.2013. URL: http://mitpress-ebooks.mit.edu/product/from-social-butterfly-toengaged-citizen.

Gurstein, M. (2000). Community informatics: Enabling community uses of information and communication technology. In Gurstein, M. (ed.), Community informatics: Enabling communities with information and communication technologies. Hersey PA: Idea Group Publishing, pp. 1-32.

Gurstein, M. (2007). What is community informatics (And why does it matter). Milan: Polimetrica. 
Habermas, J. (1989). The structural transformation of the public sphere: An inquiry into a category of bourgeois society. Cambridge, Mass.: MIT Press.

Hampton, K. \& Wellman, B. (2002). The Internet and everyday life. Blackwell.

Harrison, M. (1995). Visions of Heaven and Hell. London: Channel 4 Television.

Kling, R. (1996). Computerization and controversy. Value conflicts and social choices. San Diego: Academic press.

Kollock, P. \& Smith, M. (eds.). (1998). Communities in cyberspace. London: Routledge.

Laffin, M. \& Ormston, C. (2013). Disconnected communities? ICT, policy learning and the lessons for central-local relations. Public money \& management, 33(3), 185-191.

London, S. (1997). Civic networks: Building community on the Net. In Composing Knowledge: Readings for College Writers. Boston, MA: Bedford/ St. Martins.

Longford, G. (2005). Community networking and civic Participation in Canada: A background paper, CRACIN Working Paper No. 1, Canadian Research Alliance for Community Innovation and Networking/Alliance canadienne de recherche pour le re'seautage et l'innovation communautaires.

Preece, J. (2000). Online communities: Designing usability, supporting Sociability. New York: John Wiley.

Putnam, R. D. (2000). Bowling alone: The collapse and revival of American community. New York: Touchstone.

Rheingold, H. (1993). The virtual community: Homesteading on the electronic frontier. London: Secker and Warburg.

Schmidt, J. (1997). Virtual culture. Identity and communication in cybersociety. (pp. 81-101). Sage.

Schuler, D. (1996). New community networks wired for change. New York: Addison-Wesley Pub. Co.

Schuler, D. \& Day, P. (eds.). (2004). Shaping the network society: The new role of civil society. Cambridge, Mass.: The MIT press.

Schüller, A., van Trijp, R. \& Prins, D. (2008). Businessplan Buurtleven.nl Periode 2008-2013. 
Tönnies, F. (2002). Community and society = Gemeinschaft und Gesellschaft. Mineola, N.Y: Dover Publications.

Williams, R., Slack, R. \& Stewart, J. (2000). Social learning in multimedia: Final report (EC Targeted Socio-Economic research Project: $4141 \mathrm{PL}$ 951003). Edinburgh: Research Centre for Social Sciences, University of Edinburgh.

Wyatt, S. (1998). Technology's arrow: The development and use of information networks for public administration in Britain and the United States. UPM, Maastricht. 